\title{
EJSBS
}

The European Journal of Social \&

Behavioural Science

ISSN: 2301.2218 (ONUINE)
OPEN ACCESS

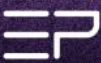

The European Journal of Social and Behavioural Sciences

EJSBS Volume XXX, Issue III (eISSN: 2301-2218)

\section{INNOVATING CULTURALLY RESPONSIVE PEDAGOGY WITH THE CRAFT FUN KIT (CFK)}

\author{
Siti Zuraida Bt Maaruf**, Mohamad Nizam Bin Mohamad Helmi ${ }^{\text {b }}$ \\ ${ }^{a}$ Universiti Teknologi MARA (UiTM), Selangor, Malaysia \\ ${ }^{b}$ Raudhah College, Cyberjaya, Malaysia
}

\begin{abstract}
This study presents findings on the implementation of a teaching learning tool to enhance culturally responsive learning to enhance awareness of and knowledge about Malaysian traditional crafts in Visual Art classes. Most research in the Malaysian context exploring culturally responsive pedagogical methods has investigated theoretical and general properties, but few have attempted to investigate innovating tools to improve teaching and learning in schools and higher education. New methods with interesting features to teach certain cultural elements will not only trigger learning but can also instil the targeted values in students especially those living in multi racial countries. Using the Design and Development Method for one such tool, this study presents an evaluation of the Craft Fun Kit utilised by an experienced Visual Arts Education teacher in his class to study the students' responses to and acceptance of the tool both to enhance learning and multicultural awareness. The overall results found that the Craft Fun Kit is relevant and appropriate as a learning tool which can enable students to attain Visual Art education learning outcomes at the secondary school level in Malaysia.
\end{abstract}

tools

Keywords: Culturally responsive learning, supporting material, Visual Art Education, teaching learning

(C) 2021 Published by European Publisher. www.europeanpublisher.com

\footnotetext{
${ }^{*}$ Corresponding author. $+6017-6525400$

E-mail address: sitiz610@uitm.edu.my
}

doi: 10.15405/ejsbs.303 
https://doi.org/10.15405/ejsbs.303

eISSN: 2301-2218 / Corresponding Author: Siti Zuraida Bt Maaruf

Selection \& Peer-review under responsibility of the Editors

\section{Introduction}

\subsection{Supporting materials in the classroom}

Teachers need to constantly keep themselves informed about current socio-educational developments not only to improve teaching but also stimulate learning in order for them to be able apply appropriate techniques in delivering certain learning objectives. It is essential that teachers constantly innovate their approaches to make teaching and learning not only more interesting but, more importantly, meaningful for both themselves and their students. Bharambe (2012) posited that the foundation of effective teaching method lay in meeting students' needs within the nature of the content, which necessitates teachers to focus on what students need to learn and how they can learn it. It is, undoubtedly, a constant effort for teachers to identify meaningful and effective teaching methods while creating an engaging learning environment. Therefore, Kesici and Cavus (2019) contend that teachers would need to apply teaching techniques that enhance students' involvement while keeping their efforts focussed on attaining the learning objectives.

Azman and Mustapha (2014) posit that, compared to just verbal explanation or description, the implementation of supporting materials in learning activities can assist teachers in clarifying concepts; thus, enabling the students to understand the learning content better. The implementation of supporting materials during learning facilitates the process of teaching and learning by ensuring that the teacher can accomplish the teaching objectives stipulated in the syllabus (Azman \& Mustapha, 2014).

Supporting materials are implemented into classroom learning activities to facilitate the process of teaching and learning as well as to ensure that teacher can accomplish teaching objectives in accordance with the syllabus. For one thing, utilizing supporting materials in the classroom will eliminate students' boredom resulting from passive one-way teaching strategies as well as over reliance on textbooks and workbooks.

A systematic instructional design is essential to construct and implement an active teaching and learning process to attain the stated learning objectives. In their research, Zaid and Mohamad (2010) confirm that interactive supporting materials are effective teaching aids that can stimulate an environment for active teaching and learning to occur.

Ohwojero (2015) explained that a teaching aid is a pedagogical tool that assists in the delivery of information by the teachers to students in the classroom. The use of teaching aids such as computers, audio-visual aids, slideshows, and animation software used to present information in an interactive manner have shown to increase and sustain students' motivation.

The combination of conventional teaching materials such as textbooks and teaching aids with inventive technology is common in teaching and learning in schools nowadays. It 
https://doi.org/10.15405/ejsbs.303

eISSN: 2301-2218 / Corresponding Author: Siti Zuraida Bt Maaruf

Selection \& Peer-review under responsibility of the Editors

has been proven that multimedia technology plays an important role in ensuring that learning objectives can be achieved by students (Kamaruddin, 2015).

\subsection{Culturally responsive education}

Continuous efforts to improve culturally responsive education have received a lot of attention with the rise of societal and individual awareness on cultural differences with digital social media being one of the major conveyors of news and information. According to Siti Zuraida \& Saedah (2013) "Culturally responsive pedagogy is a teaching and learning approach developed based on the knowledge of culture and extant experiences that student from multi-ethnic backgrounds possess, built upon references and the performance styles of these multiracial students so as to make the learning process more relevant and effective to them" (p. 1171). Visual Art Education (VAE) has become one of the means to transmit culturally responsive elements in a multiracial country like Malaysia (Siti Zuraida \& Saedah, 2013). This has become especially important with the increase of various concerns regarding the disruption of racial unity in Malaysia, particularly in educational settings. A study by Noormaizatul, Noraini, Nurul Husna and Radzuwan (2021) posits that due to the "ever-changing and imbalance in the educational system's administration", serious concerns have emerged with regard to racial unity which according to them, "stems from the basis that schools and universities are the centre grounds where racial identity and culture are transmitted and thus the constantly changing policy certainly impacts on individuals" (p. 151). These educational vicissitudes occurring in Malaysia makes it crucial for teachers to create teaching environments that encourage unity and tolerance in the classroom. Najeemah (2005) believes that such efforts would improve students' knowledge on the diverse cultural elements that exist in Malaysia while increasing their awareness on the need for cultural tolerance. Siti Zuraida et. al (2017) claim that with the rise of societal concerns and awareness of cultural tolerance in a culturally diverse Malaysian society, incessant efforts are vital in instituting educational reforms and pragmatic classroom practices.

\section{Problem Statement}

The lack of knowledge on other ethnicities' heritage and customs may be a contributing factor that may affect tolerance and unity especially in a multi-ethnic society with a diverse cultural background such as Malaysia. Cultural prejudices may arise due not only to unfamiliarity but also a misinformed society leading to racial polarization and distrust (Noormaizatul, Noraini, Nurul Husna, \& Radzuwan, 2021) which would impact the social and economic well-being of the nation. It is vital, therefore, that accurate and effective educational 
https://doi.org/10.15405/ejsbs.303

eISSN: 2301-2218 / Corresponding Author: Siti Zuraida Bt Maaruf

Selection \& Peer-review under responsibility of the Editors

approaches be instituted to provide precise information regarding various cultures and heritage that exist in a multicultural society and the best place to do this is at school where children are being exposed to knowledge about various concepts and issues pertaining to their society and the world. Regardless of the many efforts and educational reformation undertaken by Malaysian education stakeholders, there is still much room for improvement. The Malaysian government had introduced the the Student Integration Plan for Unity known as the RIMUP (Rancangan Integrasi Murid Untuk Perpaduan) locally, in its scheme to promote the ideal 'unity in diversity' through enhancing interaction in public schools. The RIMUP aims to improve ethnic relations and is elementary for the success of future education policies (Segawa, 2019). Many conflicting ideas between races and ethnicities have become more rampant in the current socio-political climate in Malaysia with a number of policies being challenged at the expense of the national constitution and public peace. Education can bridge and mend the differences in order to establish a neutral space to instil tolerance while stimulating multi-cultural awareness.

Therefore, the Craft Fun Kit (CFK) was developed as an innovative teaching learning approach to introduce a new teaching aid that presents culturally responsive art lessons may open a window to view multi-cultural elements that exist in Malaysia. The present Visual Art Education (VAE) syllabus includes various craft projects for students to undertake; however, the process of producing the craft only emphasizes on the elements and principles of art (Malaysian Secondary School New Curriculum for Visual Art Education, 2002). To overcome this limitation, the CFK was developed as a culturally responsive tool to not only assist students in their craft production but create awareness and appreciation of multi-cultural elements in society.

\section{Research Objectives}

The current study seeks to provide insights in an identifying a selected VAE teacher's perceptions on the feasibility of the CFK as a teaching learning tool to teach the craft topic at the secondary school level in Malaysia. More importantly, this research also seeks to answer if the CFK be used as tool to create awareness and appreciation of multi-cultural elements in society.

\section{Research Questions}

The following range of questions emerged from an indepth consideration of the general research objectives for this study and a number of associated considerations related to the 
https://doi.org/10.15405/ejsbs.303

eISSN: 2301-2218 / Corresponding Author: Siti Zuraida Bt Maaruf

Selection \& Peer-review under responsibility of the Editors

teaching and learning of craft making as a topic in the VAE classroom. The researchers wished to find out if the CFK could

4.1 be effectively used by students to create their craft with ease.

4.2 be effectively used to engage students' interest and attention in the related learning topics.

4.3 enable students to complete their craft projects within the stated classroom duration.

4.4 be effectively used as a practical tool by students in the classroom.

4.5 be used effectively for outside classroom learning.

4.6 be used effectively as a supplementary tool in craft making classes.

4.7 create awareness and appreciation of multi-cultural elements in Malaysian society.

\section{Methodology}

\subsection{Design and Developmental Research Approach}

The research design for this study was based on the Design and Development Method (Richey \& Klein, 2007) that focuses on the development of a culturally responsive pedagogy teaching tool known as Craft Fun Kit (CFK). The Design and Development method is a systematic and consistent process to develop and evaluate new instructional tools for internal effectiveness. It comprises three phases that the researcher needs to complete; phase one is the need analysis; phase two is the development and design; and phase three is the implementation and evaluation. This paper will only describe results and findings of Phase 3 which is the Implementation and Evaluation stage which was preceded by Phase 1 of the study which is the Needs Analysis, while Phase 2 covered the Design and Development stage of the tool.

\subsection{Sample and Data collection}

Data was collected through purposive sampling using one experienced Visual Arts Education teacher utilising the tool during a classroom session. Hence, data may not be generalised to the larger population. The selected teacher has ten years' experience in teaching Visual Art in school at the upper secondary level and is competent in craft making. The reason for using only a single participant teacher for this study was to obtain the perceptions of one experienced teacher at the initial stage of using the CFK in an authentic classroom setting to uncover the tool's strengths and weakness before proceeding to a larger scale exploration. The researchers felt that the information obtained from this one participant teacher would help shed light on the feasibility in line with the research objectives before proceeding with an extended implementation with a larger sample of teachers. 
According to Palinkas et al. (2015), purposive sampling is a common technique used in qualitative research "for the identification and selection of information-rich cases for the most effective use of limited resources" (Patton, 2002, cited in Palinkas, 2015, n.p.) using "individuals or groups of individuals that are especially knowledgeable about or experienced with a phenomenon of interest" (Cresswell \& Plano Clark, 2011, cited in Palinkas, 2015, n.p.). Purposive sampling also incorporates the elements of "availability and willingness to participate, and the ability to communicate experiences and opinions in an articulate, expressive, and reflective manner" (Bernard, 2002; Spradley, 1979, cited in Palinkas, 2015, n.p.). Furthermore, in utilising purposive sampling, researchers fall back on their own knowledge and judgment when selecting participants out of the population to participate in the study. Hence, the purposive sampling technique, also known as judgment sampling, refers to the deliberate choice of a participant due to the qualities the participant possesses (Etikan, Musa, \& Alkassim, 2016). Purposive sampling is a non-random technique which allows the researcher to select participants based on their knowledge and experience who are willing and able to provide the necessary information required to fulfil the study objectives. Using the purposive sampling technique allows for a single participant to participate in the study as it is a non-generalization sampling technique. Hence, for this study, the participant was selected based on his strong profile and experience in the working field.

Table 1. Phase 3 - Implementation and evaluation

\begin{tabular}{cccc}
\hline Sample & Number of Sample & Sampling Method & Data collection method \\
\hline VAE teachers & 1 & Purposive Sampling & $\begin{array}{c}\text { Semi-structured } \\
\text { Interview }\end{array}$ \\
\hline
\end{tabular}

\subsubsection{The Craft Fun Kit}

The CFK contains 5 different Craft tools and 1 Interactive Instructional Demonstration CD (see Figure 1). The contents of the CFK are as follows:

1. Interactive CD Demonstration of crafts.

2. Batik Canting ${ }^{1}$ tools and materials.

3. Batik Tye \& Dye tools and materials.

4. Wood and Lino Carving tools and materials.

\footnotetext{
${ }^{1}$ Batik canting or 'tjanting' (in the Indonesian language) is a traditional hand tool that is used to apply wax in lines and fine dots on a cloth to create beautiful batik designs.
} 
5. Printmaking tools and materials.

6. Tekat $^{2}$ Embroidery tools and materials.

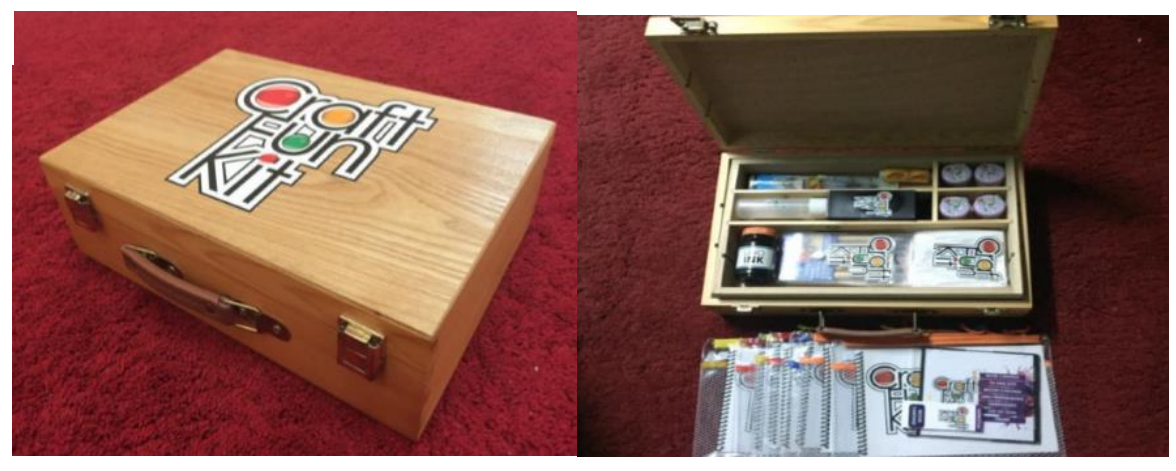

Figure 1. The Craft Fun Kit (CFK) Packaging and other craft material components

\subsubsection{Semi-structured Interview as a data collection instrument}

Upon completing the Implementation stage of using the CFK tool in the classroom, the researchers employed a semi-structured interview as the data collection instrument to gather the VAE teacher participant's perceptions and opinions based on his experiences accumulated while using the CFK in classroom. Fraenkel, Wallen, and Hyun (2012) have affirmed that the semi-structured interview is an effective means of collecting data for qualitative research as "this method allows the researcher to collect open-ended data, to explore participant thoughts, feelings and beliefs about a particular topic...to understand the thoughts, beliefs and experiences of individuals" (DeJonckheere \& Vaughn, 2019, n.p.). Furthermore, "semi structured interviewing can be a powerful tool for ... researchers to use to understand the thoughts, beliefs, and experiences of individuals" (DeJonckheere \& Vaughn, 2019, n.p.).

A narrative analysis was used to elicit the data from the interview session with the participant teacher as narrative inquiry emphasises participants' authentic experiences as viable sources of information. Data collected for the analysis was transcribed verbatim from the interview and a thorough content analysis was conducted to glean information that answered the research questions.

\footnotetext{
${ }^{2}$ Tekat is a type of traditional Malay couched embroidery that employs the use of gold threads on a background of richly coloured velvet, generally maroon.
} 
The implementation of the CFK in the classroom was conducted by getting the teacher to use the CFK in his VAE classroom to teach the topic on craft making. Figure 2 below show some of the activities that were conducted as part of the implementation for this study.
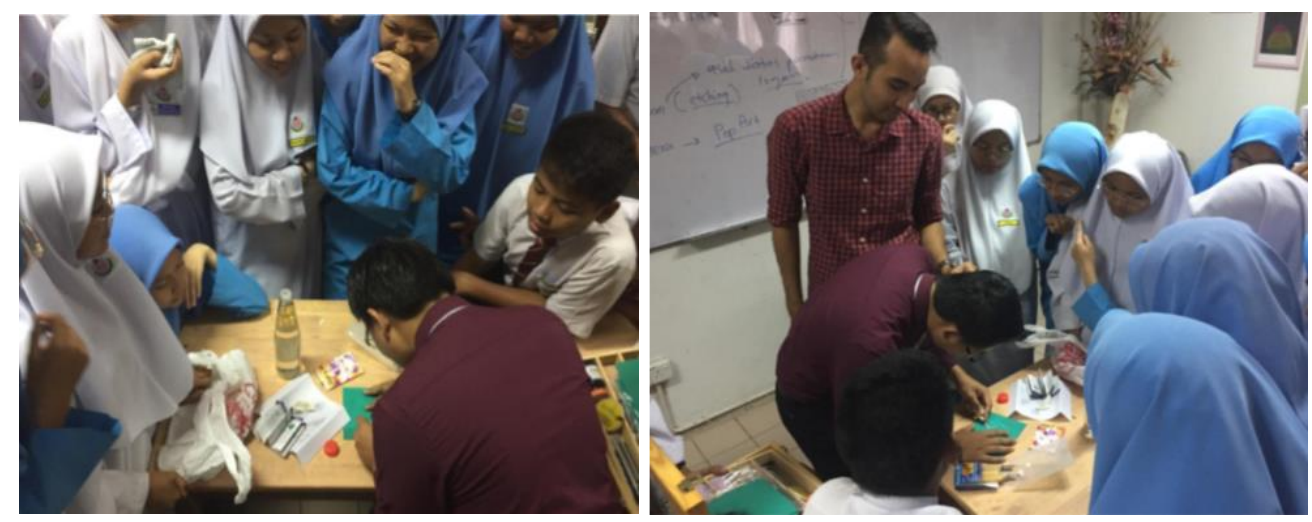

Figure 2. The teacher demonstrating lino print making craft using the CFK in class

\section{Findings and Discussion}

The evaluation phase is crucial as highlighted by Mohd Khairul and Siti Zuraida (2019) as this stage would provide the researchers with the evidence of the feasibility of the tool in the VAE classroom. The discussion of findings in Phase 3 of this study reveals the insights of the VAE participant teacher regarding the feasibility of the CFK. The findings and discussion are presented as responses to the research questions.

\subsection{Can the CFK be used effectively by students to create their craft with ease?}

The craft making topic has numerous interesting activities for the students to undertake in the VAE classroom. The CFK provides a variety of crafts that teachers and students can try their hand at related to creating crafts that reflect the multi-cultural elements in the Malaysian context. The analysis revealed that both the teacher and students were able to create or make their craft with ease using the CFK. According to the teacher, the CFK is convenient to use as all the equipment needed and the instructions are in the kit which is portable. According to the teacher's response:

"Okay well (fillers) in my opinion (fillers) after trying this Craft Fun Kit in the classroom, (fillers) I found that it is very easy to use because (fillers) the all the equipment necessary to create the craft is already in the kit (fillers) so we only need to use the materials in the tool which are based on the topic we are teaching on that day... plus, it is very easy to carry around. (Fillers) there, the 
https://doi.org/10.15405/ejsbs.303

eISSN: 2301-2218 / Corresponding Author: Siti Zuraida Bt Maaruf

Selection \& Peer-review under responsibility of the Editors

steps in the kit are already provided to show how to create the craft we want to make. I believe that this tool will facilitate students' craft making"

6.2. Can the CFK be effectively used to engage students' interest and attention in the related learning topics?

With numerous topics related to craft making in the syllabus, the participant teacher said that students like to be challenged with something new to do in making crafts which would increase their enjoyment and engagement in the hands-on experience. The teacher's response is displayed as below.

"Okay (pause) after trying this Craft Fun Kit myself in class, (fillers) and observing the students' reaction while using the tool in the class, I can vouch that it is able to attract the students' attention...Oh well (pause) I believe that's because the Craft Fun Kit itself with all the materials is very attractive and triggers the students' interest and keeps them engaged in their craft making task."

6.3. Can the CFK effectively save on students' classroom learning time in completing their craft making?

Despite a longer class duration allocated for the VAE subject, students are usually unable to complete the activity or task given in the classroom. However, the analysis revealed that the CFK facilitated the students in completing their craft making task within the allotted time in the classroom. This is a pertinent finding since, with the CFK, students can now complete their tasks in class compared to completing it as homework. According to the teacher:

"(Fillers)in my opinion (fillers) as all the equipment is already in the kit, it makes it easy to use and saves time because the kit itself is just as easy to carry around. It saves time in terms of the students having to look for materials to complete their task. What teachers need to do is to be sure to check that all the items necessary to complete the task that are in the kit and ready to use in the classroom."

\subsection{Can the CFK be effectively used as a practical tool by students in the classroom?}

Students can easily get overwhelmed by the number of materials needed to complete a craft project. The participant teacher disclosed that students usually get demotivated due to the number of materials that they need to bring to the classroom in order to complete their craft project. However, with the CFK, such concerns can be overcome because the kit contains all 
https://doi.org/10.15405/ejsbs.303

eISSN: 2301-2218 / Corresponding Author: Siti Zuraida Bt Maaruf

Selection \& Peer-review under responsibility of the Editors

the tools needed for craft projects in the VAE classroom. It is important to emphasise the potability value of the CFK when discussing its practicality value. The teacher says:

"In my opinion, yes... it is extremely practical to use in class (fillers)because the Craft Fun Kit itself is not bulky and the materials stored in the Craft Fun Kit (fillers) makes it really easy to take the kit anywhere... this is an important consideration for students ...they already have a lot of ...(fillers) materials to bring to school everyday...so an additional tool ...should not inconvenience them further"

\subsection{Can the CFK be used effectively for outside classroom learning?}

The topic on craft making in the VAE syllabus has always been an interesting activity to have in the classroom. Often, many of the activities require the teacher to demonstrate how to make certain crafts $\mathrm{s}$ which could be time consuming with the limited time allocated for the subject weekly. However, since the CFK is equipped with easy-to-follow instructions, students can use the kit without any supervision from the teacher which means that it can also be used outside the classroom setting. This was supported by the teacher:

“(Fillers) after using and trying out the activities on my own and with my own students also trying it out, I can say that (fillers) students can easily use the Craft Fun Kit without teacher supervision. (Fillers) okay (pause) because the instructions are already provided for every step to complete the project. This is also very good as they can easily complete the craft projects at home...(fillers) unlike other subjects, art work cannot be completed within a specific time ...(fillers) due to the nature of the work which (fillers) requires reflection and contemplation...in order to create the best artistic work"

6.6. Can the CFK be used effectively as a supplementary tool in craft making classes?

Effective teaching aids in the classroom are always beneficial in terms of enhancing student engagement during lessons. This is especially valuable as when students are engaged in the learning activities, learning becomes more meaningful. Since it has already been established that the CFK can be utilised as an effective teaching aid in terms of its practicality, time saving and engagement value, it can be considered an effective supplementary teaching tool in the VAE classroom. This was conveyed by the teacher:

“Okay (fillers)... in my opinion, tools such as Craft Fun Kit should be used to help teachers to facilitate the learning process of topics related to this traditional craft making because often this traditional craft making is mostly 
https://doi.org/10.15405/ejsbs.303

eISSN: 2301-2218 / Corresponding Author: Siti Zuraida Bt Maaruf

Selection \& Peer-review under responsibility of the Editors

carried out in the studio. The items involved are bulky and difficult to carry around. So, with this Craft Fun Kit, (fillers)in my opinion it's easy for the teacher to integrate it as a learning activity classroom and also outside the classroom, in case students could not complete their projects on time."

\subsection{Can the CFK create awareness and appreciation of multi-cultural elements in Malaysian society?}

The CFK is a kit that contains a number of materials which students can use to create their craft projects. One of the aims of the CFK is to enhance students' awareness and appreciation of multi-cultural elements in Malaysian society. According to the teacher, this is facilitated by the CFK because:

"okay...this is a good question...for me (filler)the CFK is not like other tools because the materials in the kit...(filler) not just for making crafts but also can expose the students to the multicultural crafts available in Malaysia (fillers)...you see (filler) the CFK has samples of craft motifs from Malay, Chinese and Indian cultures for five different crafts...this is really good... can promote students' awareness and understanding of the symbols and motifs from different cultures (fillers)... when students use these to create their craft projects...for me this is an excellent way to expose the children to ...(fillers) variety in Malaysian art"

\section{Conclusion and Implications}

The findings gathered from the interview analysis have revealed that the CFK was successful in alleviating many of the classroom associated problems like time management and portability of tools faced by students learning the craft making topics in the VAE syllabus in Malaysian schools. The findings reveal that the CFK was effective in facilitating the students' learning of the craft making topics in multiple ways as addressed by the research questions. According to the expert teacher's feedback after implementing the CFK in the class, the tool was able to:

- be effectively used by students to create their craft with ease;

- be effectively used to engage students' interest and attention in the related learning topics;

- enable students to complete their craft projects within the stated classroom duration;

- be effectively used as a practical tool by students in the classroom;

- be used effectively for outside classroom learning; 
- be used effectively as a supplementary tool in craft making classes; and last but not least

- create awareness and appreciation of multi-cultural elements in Malaysian society.

All this was made possible as although the kit is easy to handle and to be carried around, its compact features can still promote meaningful learning. The tools included in the kit are uncomplicated and appealing for craft making that can trigger interest which subsequently promotes engagement among users. Classroom activities require interesting and creative teaching materials to inspire students to learn (Siti Zuraida \& Saedah, 2013).

Making crafts should not be limited to performing activities in the classroom but it should be encouraged beyond the classroom setting. Therefore, the CFK is an appropriate tool that can promote this as it can be carried around in ease and the activities can be done without teachers' supervision with clear instructions are provided in the kit. Most importantly, in line with the aims of culturally responsive pedagogy, the CFK was able to achieve the goal of stimulating awareness and understanding of the multi-cultural artistic variety in Malaysia.

The CFK is worth consideration by VAE curriculum developers as a tool with great potential for classroom use not only to comply with curriculum standards for the teaching and learning of VAE, but also as a tool that can promote multi-cultural understanding in a diverse society like Malaysia.

Despite the highly promising results for the use of the CFK in this study, it must be stated that this study was limited to obtaining the perceptions of one teacher using the tool in his class. As such, the results may not be generalised to the entire population of VAE teachers and students in Malaysia. The CFK should be subjected to further investigation in terms of widening the teacher and student sample base to validate its relevance and applicability as a VAE learning tool.

\section{Acknowledgements}

The author(s) declare that there is no conflict of interest.

\section{References}

Azman, M. N. A., Azli, N. A., Mustapha, R., Balakrishnan, B., \& Isa, N. K. M. (2014). Penggunaan Alat Bantu Mengajar ke Atas Guru Pelatih Bagi Topik Kerja Kayu, Paip dan Logam [Use of teaching aids by teacher trainees for woodwork, pipe and metal topics]. Journal Sains Humanika, 3(1), 77-85. https://doi.org/10.11113/sh.v3n1.530

Bharambe, I. (2012). Effectiveness of Mind Mapping in Educational Psychology. Indian Streams Research Journal, 2(4), 10-18. https://doi.org/10.9780/22307850

DeJonckheere, M., \& Vaughn, L. (2019). Semi structured interviewing in primary care research: a balance of relationship and rigour, Family Medicine and Community Health 7(2):e000057. https://doi.org/10.1136/fmch-2018-000057 
Etikan, I., Musa, S. A., \& Alkassim, R. S. (2016). Comparison of Convenience Sampling and Purposive Sampling. American Journal of Theoretical and Applied Statistics, 5(1), 14. https://doi.org/10.11648/j.ajtas.20160501.11

Fraenkel, J. R., Wallen, N. E., \& Hyun, H. H. (2012). How to Design and Evaluate Research in Education. New York: McGraw Hill.

Kamaruddin, N. (2015). Understanding Patterns of Interactive Courseware Use Within Malaysian Primary Smart Schools. Malaysian Online Journal of Educational Technology, 3(1), 49-56.

Kesici, A. E., \& Cavus, B. (2019). The Evaluation of Teacher Training Programs in the United States of America in Terms of Student-Centered Practices Used in Class. Journal of $\begin{array}{llll}\text { Education } \quad \text { and Training } & \text { Studies, } & 7(10), & \text { 78-89. }\end{array}$ https://doi.org/10.13140/RG.2.2.11396.37763

Mohd Khairul Azlan, R., \& Siti Zuraida, M. (2019). The Evaluation and Implementation on the Development of Stimulation Setting using CTML Model. Social and Management Research Journal, [S.l.], 16(1), 41-54. https://doi.org/10.24191/smrj.v16i1.6080

Najeemah, M. Y. (2005). Multicultural Education Practice among Teachers in National Secondary Schools: A Case Study in Kedah. Malaysian Journal of Educators and Education, 20. 97-111.

Noormaizatul Akmar Muhamad Nasir, Noraini Mohd Nor, Nurul Husna Yaacob \& Radzuwan Ab Rashid (2021). A Review of Racial Microaggression in Malaysian Educational System and Its Higher Education Institutions, International Journal of Higher Education, 10(2), 151-163. https://doi.org/10.5430/ijhe.v10n2p151

Ohwojero, C. J. (2015). Teaching Aids a Special Pedagogy Tool of Brain Development in School Children, Interest and Academic Achievement to Enhance Future Technology, 6(29), 92-101.

Palinkas, L. A., Horwitz, S. M., Green, C. A., Wisdom, J. P., Duan, N., \& Hoagwood, K. (2015). Purposeful sampling for qualitative data collection and analysis in mixed method implementation research, Adm Policy Mental Health, 42(5), 533-544. https://doi.org/10.1007\%2Fs10488-013-0528-y

Richey, R. C., \& Klein, J. D. (2007). Design and Development Research: Methods, Strategies, and Issues. Lawrence Erlbaum Associates, Inc

Secondary School New Curriculum for Visual Art Education (2002). Malaysian Ministry of Education: Dewan Bahasa \& Pustaka

Segawa, N. (2019). Ethnic Relations at School in Malaysia: Challenges and Prospects of the Student Integration Plan for Unity. Palgrave Pivot. https://doi.org/10.1007/978-98113-9857-5

Siti Zuraida Maaruf \& Saedah Siraj (2013). The state of Technology and the Arts-Interactive Multimedia in Enhancing Culturally Responsive Pedagogy. Procedia - Social and Behavioral Sciences, 103, 1171-1180. https://doi.org/10.1016/j.sbspro.2013.10.444

Siti Zuraida Maaruf, Noor Farhani Othman, Muhamad Azhar Abdullah, \& Voviana Zulkifli (2017). Multi-Ethnic Tolerance in Visual Arts Education: Teachers' Experiences with Culturally Responsive Pedagogy. Pertanika J. Soc. Sci. \& Hum. 25, 1- 10.

Zaid, N. M., \& Mohamad, F. (2010). Pembangunan Modul Multimedia Interaktif Menggunakan Pendekatan Pembelajaran Berasaskan Senario [the Development of Interactive Multimedia Module Using Scenario-Based Learning Approach], 1-18. http://eprints.utm.my/11329/ 